\title{
Uma nota sobre ilusionismos e alegorias na pintura barroca de Salvador da Bahia ${ }^{1}$
}

\author{
A Note on Illusionism and Allegory \\ in the Baroque Painting of Salvador, Bahia
}

\author{
LUÍS DE MOURA SOBRAL \\ Professor Titular no Departamento de História da Arte e Estudos \\ Cinematográficos da Universidade de Montreal, Canadá \\ Titular da Cátedra de Cultura Portuguesa, Universidade de Montreal, Canadá \\ Université de Montréal, Histoire de l'art et études cinématographiques \\ C.P. 6128 , succursale Centre-ville \\ Montréal, Québec- H3C 3J 7 - Canada \\ luis.de.moura.sobral@umontreal.ca
}

RESUMO As principais tendências da pintura no Brasil colonial podem ser estudadas na Catedral de Salvador, a igreja do antigo Colégio da Companhia de J esus. Datando dos finais do século XVII, várias séries de quadros de qualidade diversa, compõem com as esculturas dos altares um soberbo e complexo bel composto de propaganda inaciana. Para decorar o forro da Biblioteca, por cima da sacristia, os J esuítas encomendaram cerca de 1735-1736 uma monumental quadratura ao pintor português António Simões Ribeiro (?-1755). A pintura é estudada em função da tradição de decoração das bibliotecas durante a época moderna. Para além da quadratura, Simões

1 Artigo recebido em Setembro de 2006. Autor convidado. 
Ribeiro introduziu na arte brasileira as figuras alegóricas, tornando-se assim o primeiro pintor brasileiro verdadeiramente barroco e o criador da chamada Escola Bahiana.

Palavras-chave Pintura barroca brasileira; Decoração de bibliotecas; António Simões Ribeiro

ABSTRACT The main trends of the painting in colonial B razil can be studied in the Cathed ral of Salvador, Bahia, the church of the former J esuit College. Dating from the late 17th Century, several cycles of paintings on the walls and the ceiling of the sacristy, of varying quality, accomplish particular symbolic functions; in conjunction with the sculpture of the altars, they compose a complex bel composto of J esuit propaganda. To decorate the ceiling of their Library, above the sacristy, the J esuits commissioned around 1735-1736 a huge quadratura from the Portuguese born painter António Simões Ribeiro (?-1755). This painting is discussed within the tradition of Library decoration in the Modern period. Besides the quadratura, Simões Ribeiro introduced in the Brazilian art the allegorical figures and became the first full-Baroque painter in Brazil and the initiator of the so-called Bahian School.

Keywords brazilian baroque picture, library ornamentation, António Simões Ribeiro

Com um bocadinho de atenção, algumas dúzias de passos e uma escada barroca de permeio, o visitante da Catedral Basílica de São Salvador da Bahia pode facilmente apreender o essencial da pintura brasileira dos séculos XVII e XVIII'2.

Começando pela sacrista do templo, uma enorme sala rectangular de vinte e quatro metros por dez, que ocupa toda a largura da igreja por trás do altar-mor, o nosso visitante depara com uma decoração assaz comum neste tipo de locais. Dela fazem parte três séries de quadros, nas paredes, nos espal-

2 Alguns dos temas aqui expostos foram por mim anteriormente tratados em:

SOBRAL, Luis de Moura. Ut Pictura Poesis: J osé de Anchieta e as Pinturas da Sacristia da Catedral de Salvador. O Território do Barroco no Século XXI. Ouro Preto - Belo Horizonte, 2000. In: Revista Barroco, 1997-2000, 18, p.209-246.; SOBRAL, Luis de Moura. Pintura, santos y propaganda: la sacristía del antiguo colegio de los jesuitas de Salvador, Bahía, In: ARANDA, Ana María. GUTIERREZ, Ramón. MORENO, Arsenio et QUILES, Fernando (dir). Barroco Iberoamericano. Territorio, Arte, Espacio y Sociedad. Sevilha: Ediciones Giralda / Universidade Pablo de Olavide, 2001. vol. 1. p.393-403; SOBRAL, Luis de Moura. António Simões Ribeiro (ca. 1716-1755) and the art of painting in Salvador, Bahia. In : Simpósio The Arts \& the Portuguese Colonial Experience. New York: The Institute of Fine Arts, 25 de Março de 2006 (não publicada); SOBRAL, Luis de Moura. Virtus in Lusitania. Enlightenment and Anti-Enlightenment in the Portuguese Painting of the $18^{\text {th }}$ Century. In: 38th Annual Meeting. Society for Spanish and Portuguese Historical Studies. Florida International University: The Wolfsonian-FIU, 20 de Abril de 2007 (não publicada). 
dares dos arcazes e no tecto, todos de autores desconhecidos. As pinturas das paredes, sobre painéis de madeira, são de sofrível qualidade e seguramente da mão de um mal preparado artista local. Por outro lado, os quadrinhos dos arcazes, a óleo sobre cobre, foram pintados em Roma segundo os cânones estéticos mais actualizados e exigentes; trata-se, em minha opinião, das meIhores pinturas da época colonial em todo o Brasil. A decoração da sacristia compreende ainda três altares de mármore, dois importados de Portugal e um, 0 altar principal, de Roma com pinturas e imagens de vulto; um lavabo igualmente de mámore, azulejos e um tecto ou forro em caixotões de madeira, uma estrutura bastante comum no espaço cultural lusitano da época, de que existem aliás abundantes e espectaculares exemplos na própria cidade de Salvador. Este tecto está dividido em vinte e um compartimentos, todos eles decorados com grotescos envolvendo uma efígie de um jesuíta, santo, mártir ou venerável. A soberba decoração da sacristia foi executada nos finais do século XVII, entre 1683 e 1694, quando a igreja ainda fazia parte do Colégio da Companhia de J esus da então capital da Colónia.

Subamos agora as escadas que levam ao andar superior, ao salão por cima da sacristia onde os padres J esuítas haviam instalado a Biblioteca do Colégio. Nos finais do século XVII possuía ela cerca de 4000 volumes de todos os autores e sobre todas as áreas do conhecimento. Reflectindo a importância do Colégio no quadro cultural, religioso e pedagógico da Colónia, devia tratar-se de uma das mais ricas Bibliotecas da cidade. Parece que a maior parte dos livros foram levando sumiço e da antiga Biblioteca já nada resta hoje a não ser a monumental decoração do forro (fig. 1). Mas felizmente que este sobreviveu, pois trata-se de uma peça fundamental na história da arte brasileira, a primeira quadratura no Nordeste, cabeça de série de todas as outras pinturas do género na cidade e na região. 0 tecto testemunha ainda de um tipo de decoração bastante utilizado na Europa principalmente no século XVIII mas que, no continente latino-americano, só no Brasil foi de facto sistematicamente praticado.

O autor desta obra é o pintor português António Simões Ribeiro, originário de Lisboa, que a deve ter executado por volta de 1735-1736, imediatamente após a sua chegada a terras americanas. Em Portugal, Simões Ribeiro tinha adquirido justa fama como especialista de quadraturas. 0 artista trabalhou em Santarém e Coimbra, tendo nesta última cidade pintado, em 1723-1724, os tectos das três salas da chamada Biblioteca J oanina da Universidade. Especializado então na decoração de bibliotecas, um tema que conheceu o seu apogeu na época barroca, talvez então por isso tenha sido o pintor chamado ao Brasil...

Cinquenta anos, pouco mais ou menos, separam assim o tecto da sacristia e o da Biblioteca dos J esuítas bahianos. Ora é precisamente na comparação entre estas duas obras que se revela a diferença entre as mentalidades estéticas que as determinaram e entre duas concepções da arte 
da pintura. Na sacristia, o visitante interessado em identificar os retratos dos caixotões tem de ir de um lado para o outro, tomando notas, voltando-se ora para Norte ora para Sul, consoante a disposição das figuras. Obviamente, o tecto compõe um panteão ou uma galeria de J esuítas ilustres, mas só a sua relacionação com os outros elementos do programa decorativo (altares, pinturas, imagens de talha), pode levar a um total entendimento do seu significado mais profundo. Entendimento nada fácil, diga-se de passagem, perdidas que estão hoje as referências culturais que informam a complexa decoração. Formal e materialmente compartimentado, indissociável da «obra de arte total» de que faz parte, o forro da sacristia carece por conseguinte, digamos assim, de verdadeira autonomia semântica.

Nada disto ocorre na Biblioteca, onde a imensa pintura do tecto se impõe de imediato ao espectador, mal ele entra na sala. Uma única composição ocupa a superfície do forro, unificando plástica e simbolicamente o vasto espaço. De facto, a função ou a própria ideia de pintura de tectos modificou-se radicalmente no meio século que separa o rez-do-chão do primeiro andar. Subsidiária de outras formas artísticas na sacristia, a quadratura afirma na Biblioteca a sua absoluta preponderância, impondo o seu império à própria arquitectura, por ela transformada.

Que representa então a monumental composição? Umas arquitecturas pintadas que fazem de conta que prolongam as quatro paredes da sala, instalando por cima da cabeça do visitante - ou do antigo leitor - uma feérica cenografia. Observada a partir do meio da sala, a ilusão espacial acentuase, pois as linhas de fuga da composição (colunas, pilares, balaústres, esquinas das paredes) convergem para a zona central. Tudo aponta de facto para o grupo de figuras que ali se encontra, a parte «falante»e mais ambiciosa da composição (fig. 2).

Suspensos entre o azul do céu e o remate abalaustrado do (fingido) edifício, esvoaçando entre nuvens, quatro figuras monumentais observam 0 que se passa na Biblioteca, parecendo interpelar os que ali se encontram. Ao alto, uma Fama alada, leva nas mãos a trompeta e uma bandeirola com uma inscrição tirada do livro dos Provérbios $(9,1)$, A Sapiência construiu a sua casa. Trata-se de uma repetição quase literal da figura que Simões Ribeiro pintou em 1723 no Hospital de J esus de Santarém, em Portugal. As restantes três personagens compõem uma espécie de pirâmide, cujo topo é ocupado pela Sapiência Divina, levantada num trono de nuvens pelo Tempo e pela Fortuna. A Sapiência tem um ceptro na mão direita, segurando na esquerda o livro do Eclesiastes aberto no versículo 1, 14: 0 começo da sabedoria é o temor de Deus. Da sua cabeça imanam raios de sol, indicativos do seu carácter divino. Na base da pirâmide, do lado esquerdo, a figura tradicional do Tempo, um ancião de torso desnudado, com a gadanha e a ampulheta numa mão; à direita, a figura igualmente alada da Fortuna, de pé por cima da roda e com asas nos tornozelos. Note-se 
que este último motivo anda mais geralmente associado à Ocasião, uma variante da Fortuna, como se pode ver num dos Emblemas de Alciato, um livro de imenso prestígio durante toda a época barroca (fig. 3).

Que dizia então esta cena aos utentes da Biblioteca dos J esuítas, perfeitamente apetrechados na época, note-se, para decifrar tais enigmas? Primeiro, a composição celebra o Triunfo da Divina Sapiência; segundo, ela afirma que só através do Temor de Deus se pode aspirar à verdadeira sabedoria; terceiro, ela diz que o acesso ao conhecimento verdadeiro (a Sapiência) depende das circunstâncias do Tempo e da Fortuna - mas que, sendo esta propícia (a Fortuna está de pé na parte superior ou favorável da roda), não há que deixar passar a Ocasião... A composição celebra ainda, emblematicamente, o Triunfo da própria Companhia de J esus, em cuja Biblioteca a Divina Sapiência elegera domicílio. A Companhia transformada em Domus Sapientiae...

O tecto de Salvador insere-se na longa tradição da decoração das bibliotecas no Ocidente, a qual remonta inevitavelmente à Antiguidade Clássica. $\mathrm{Na}$ época barroca, em instituições eclesiásticas católicas, a temática da Sapientia é relativamente frequente. A questão que ela evoca e sintetiza é a dos dois tipos de conhecimento definidos - e opostos um ao outro - séculos e séculos atrás por Santo Agostinho. Por um lado, a Verdade Revelada por Cristo nos Livros Sagrados, acessível através da Fé; por outro, a ciência, o conhecimento limitado ao mundo natural, adquirido através da razão humana. Mesmo face ao progresso dos conhecimentos científicos e à gradual laicização da cultura própria dos tempos modernos, a instituição religiosa católica continuou a defender a primazia da Fé e da Revelação. É o que se verifica na Biblioteca de Salvador.

A criação da imagem figurada da Sapiência Divina é uma consequência directa desta permanente tensão entre Razão e Fé própria ao pensamento cristão. Graficamente a imagem surge na edição de 1613 da Iconologia de Cesare Ripa, um manual iconográfico destinado antes de tudo a artistas, intelectuais e literatos (fig. 4). Com variantes mais ou menos significativas, a Sapiência de Ripa é a seguir incorporada em decorações monumentais de bibliotecas, aparecendo assim pela primeira vez em 1644 na Congregação do Oratório de Roma. A Sapiência Divina figura aqui no caixotão de maiores dimensões do forro, sentada num trono de nuvens, numa pose semelhante à composição de Salvador. Para referir unicamente exemplos italianos, a Sapiência será ainda utilizada na biblioteca da Universidade Pontifícia La Sapienza de Roma (1661-1664), na biblioteca beneditina de San Giorgio Maggiore de Veneza (1663-1665), etc., etc. Como seria de esperar e como mais tarde se fará na Bahia, todas estas pinturas insistem na primazia da Fé.

Uma versão algo diferente da Sapiência vê-se ainda no frontispício de um livro publicado em 1635 que os J esuítas de Salvador não podiam deixar 
de conhecer pois o seu autor é um membro da Companhia, o Musei sive Bibliothecae de Claude Clément (fig. 5). Trata-se de um manual de construção e de decoração de bibliotecas, propondo o seu autor para o adorno de instituições religiosas as principais «fontes da sapiência», ou seja, as figuras de Cristo na Cruz e da Virgem Maria.

Os padres jesuítas de Évora, em Portugal, seguiram rigorosamente as recomendações de Clément, quando em 1708 decidiram decorar o tecto da Biblioteca da sua Universidade (fig. 6). Ali se vê de facto a Virgem Maria sentada num trono, coroada e com o ceptro na mão direita. Duas tarjas com inscrições identificam-na como a «Sede da Sapiência»e como a «Divina Minerva», deusa antiga das artes e das ciências. Uma escada de seis degraus, cada um deles defendido por dois leões, leva até ao trono, por trás do qual se vêem ainda seis colunas salomónicas. A Mãe de Deus, Sede da Sapiência e Trono da Sabedoria, fica assim assimilada a Salomão, o filósofo monarca do Antigo Testamento.

Como se viu, em Salvador, numa casa da mesma Ordem religiosa e que também era uma instituição de ensino, optou-se trinta anos mais tarde pela linguagem alegórica. Este tipo de linguagem, mais abstracta, possibilitava uma leitura mais aberta, menos ligada às figuras tradicionais da piedade cristã, talvez ao fim e ao cabo menos resolutamente «religiosa», ou religiosa de outra maneira. Sinal dos tempos, sem dúvida, cada vez mais informados pelas luzes da critica e da razão...

A mesma conclusão se impõe quando comparamos a criação de Simões Ribeiro com outra célebre obra brasileira. Como se sabe, uma quadratura havia sido realizada alguns anos antes no Rio de J aneiro, na capela da Ordem Terceira de São Francisco da Penitência. Ora, a parte figurada desta decoração é perfeitamente tradicional, limitando-se a episódios da iconografia franciscana e à representação de personagens históricos da Ordem.

Podemos então imaginar sem muita dificuldade a admiração com que o forro jesuíta de Salvador foi recebido nos meios cultos ou letrados da capital brasileira. 0 mundo das letras conhecia então um momento de intensa actividade, estimulado pela criação em 1724 da Academia Brasílica dos Esquecidos. Era sem dúvida este meio que melhor podia entender e saborear as novidades da arte de Simões Ribeiro. A cultura emblemática que ele introduz na pintura bahiana, responde de certa maneira a tendências há muito observadas na literatura, como se pode ver, por exemplo, na História do Predestinado Peregrino e seu Irmão Precito do jesuíta Alexandre de Gusmão, publicada em 1682, cheia de figuras alegóricas.

Com o tecto da Biblioteca dos J esuítas a arte da pintura ganha em Salvador uma dignidade e um estatuto culturais radicalmente novos. Simões Ribeiro é o pintor que faltava à «Bahia convertida em Atenas», anunciada ou retoricamente desejada pelos Académicos Esquecidos. Com ele (e não 
com o seu discípulo J oaquim Manuel da Rocha, como ainda se continua a afirmar) inicia-se a chamada «Escola Bahiana de Pintura», nele encontra a arte brasileira o seu primeiro pintor verdadeiramente moderno e plenamente barroco.

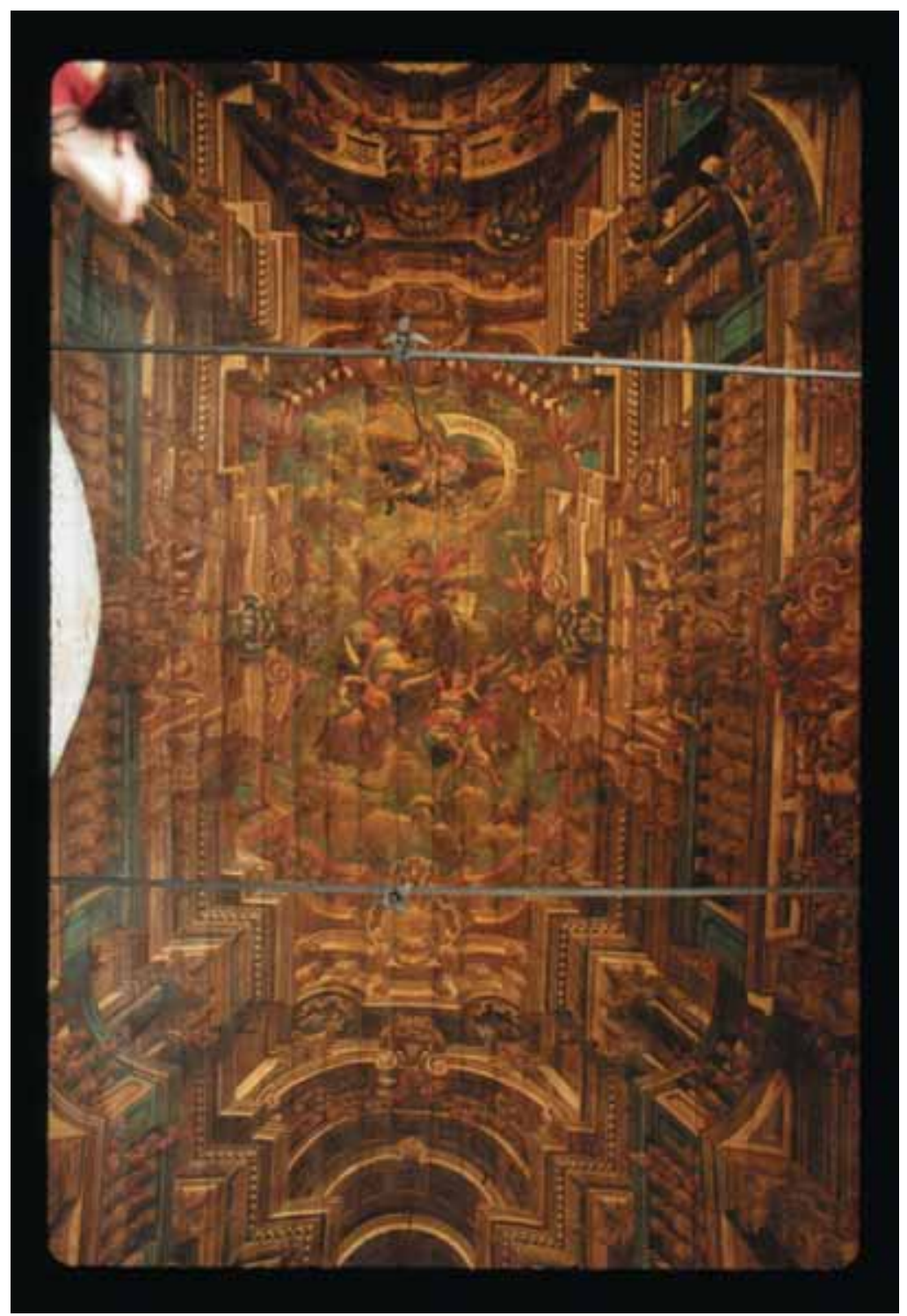

Figura 1: António Simões Ribeiro, Triunfo da Providência Divina, 1735-17, tecto da antiga Biblioteca do Colégio da Companhia de J esus, Salvador, Bahia (foto do autor). 


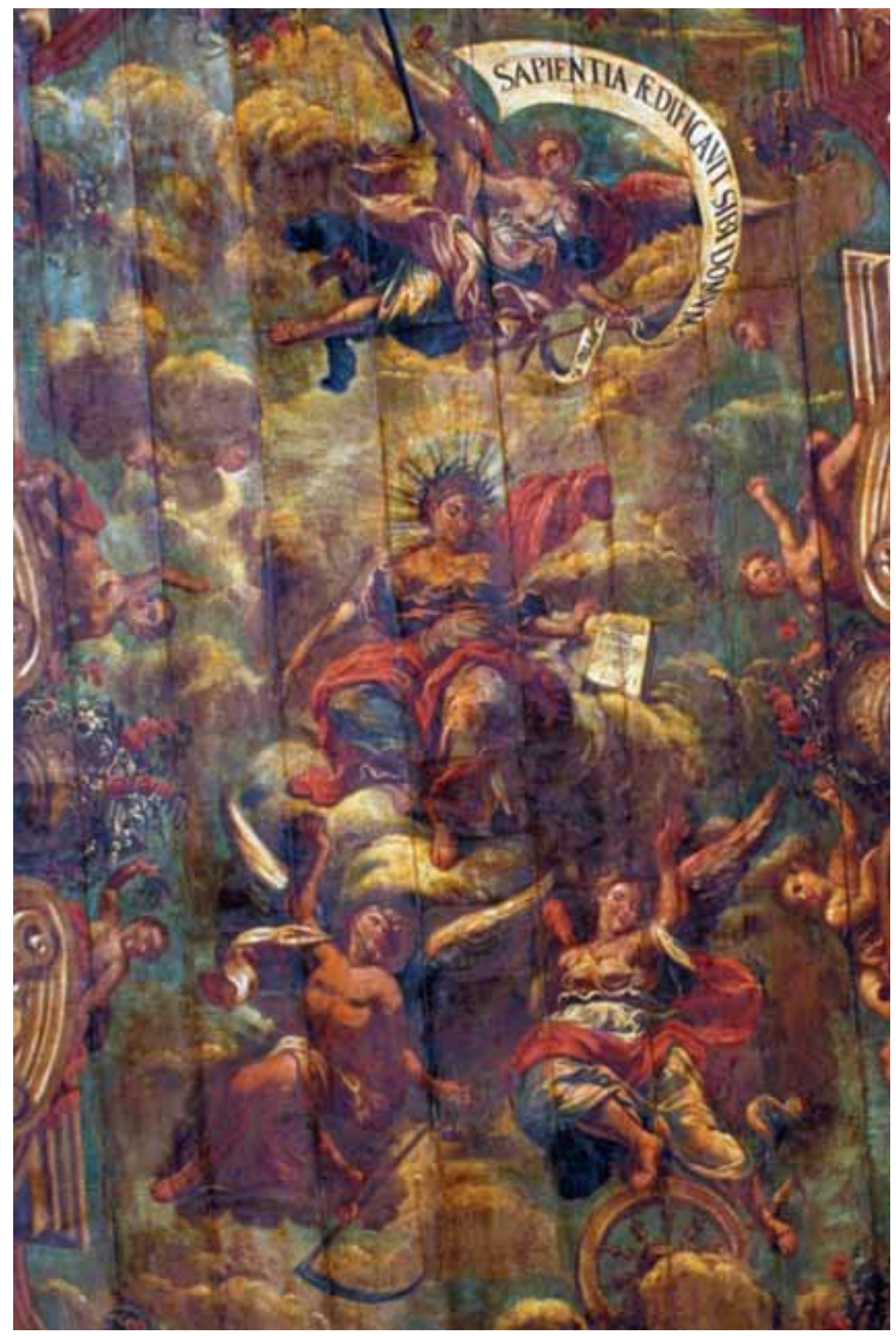

Figura 2: António Simões Ribeiro, Triunfo da Providência Divina, 1735-17, pormenor da figura 2 (foto do autor). 


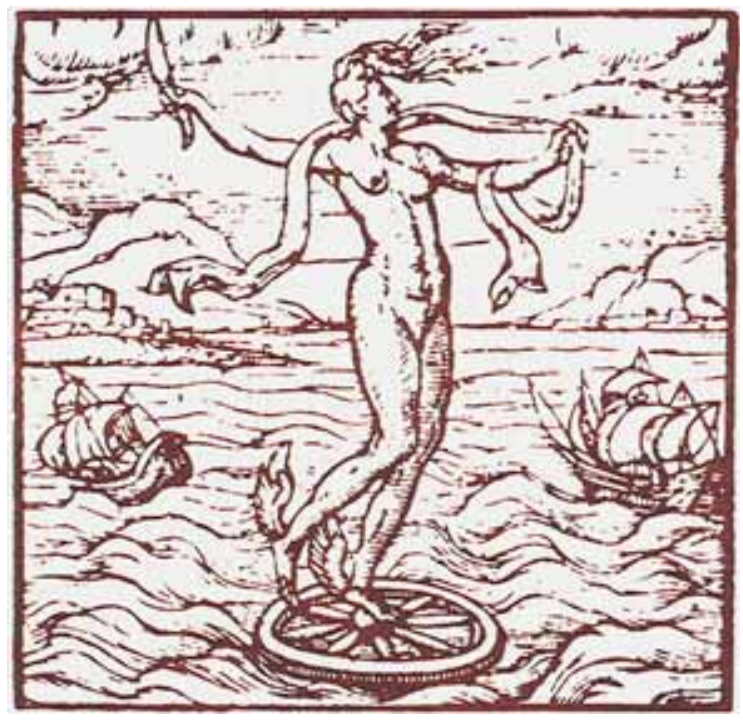

Figura 3: Ocasião, gravura tirada dos Emblemas de Andrea Alciato (1 $1^{\text {a }}$ edição, 1531).

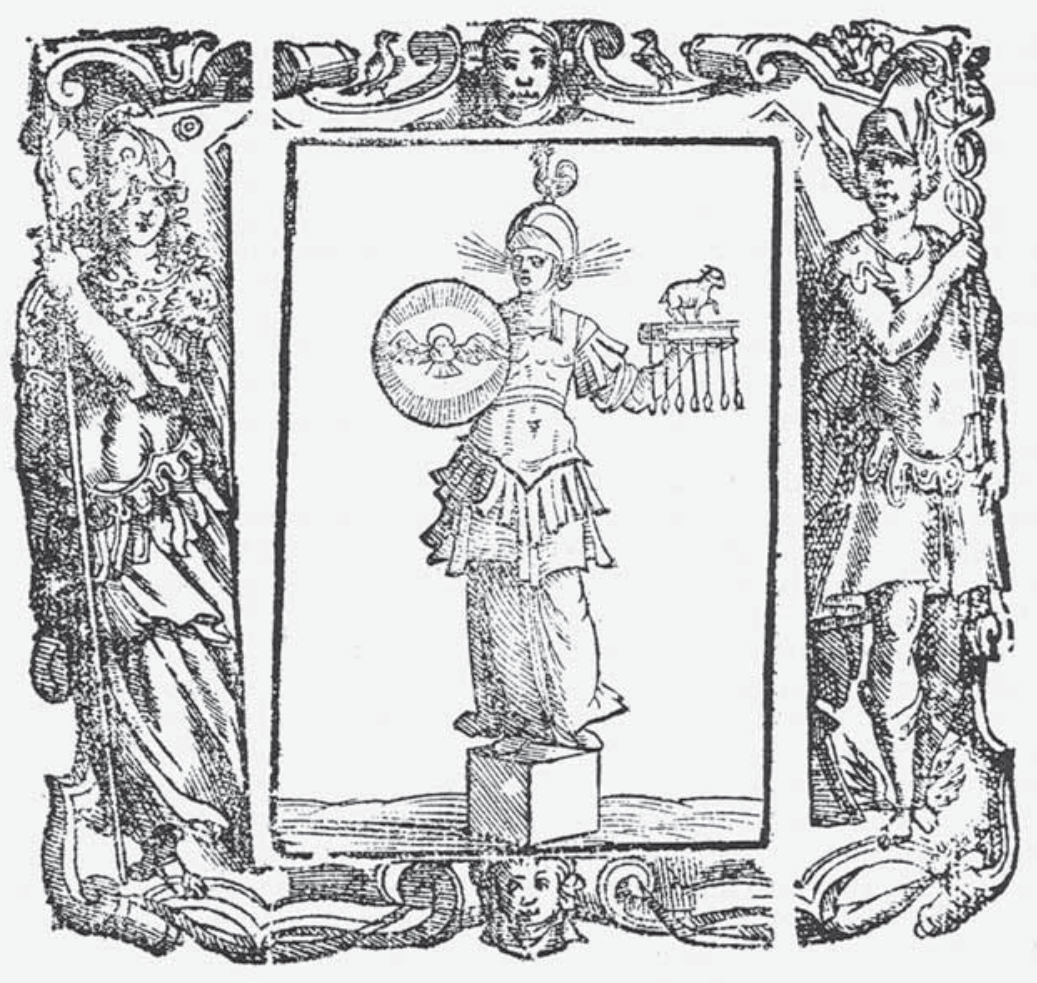

Figura 4: Sapiência Divina, gravura tirada da Iconologia de Cesare Ripa, 1613. 


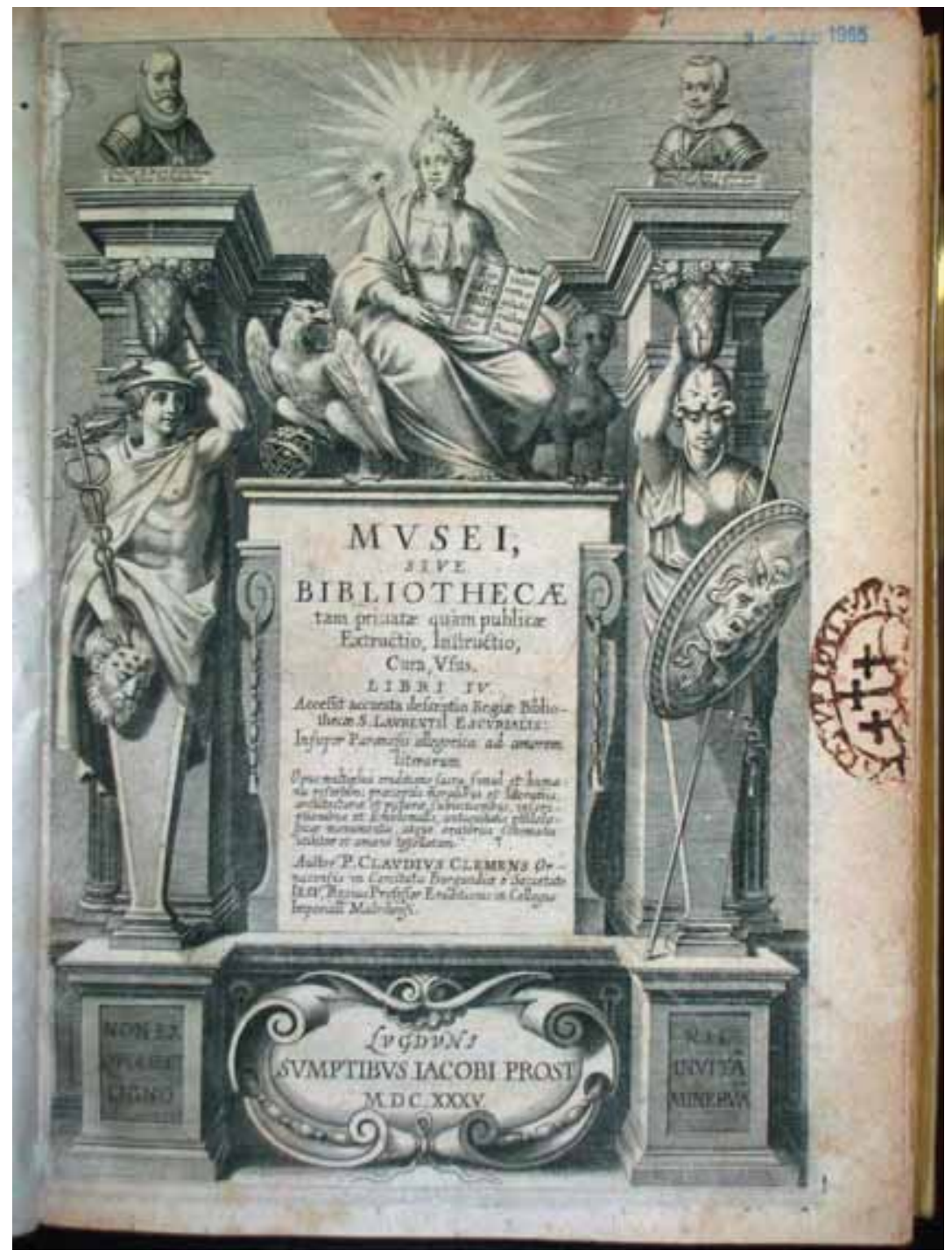

Figura 5: Frontispício de Claude Clément, Musei sive Bibliothecae, Lyon, 1635 (foto do autor). 


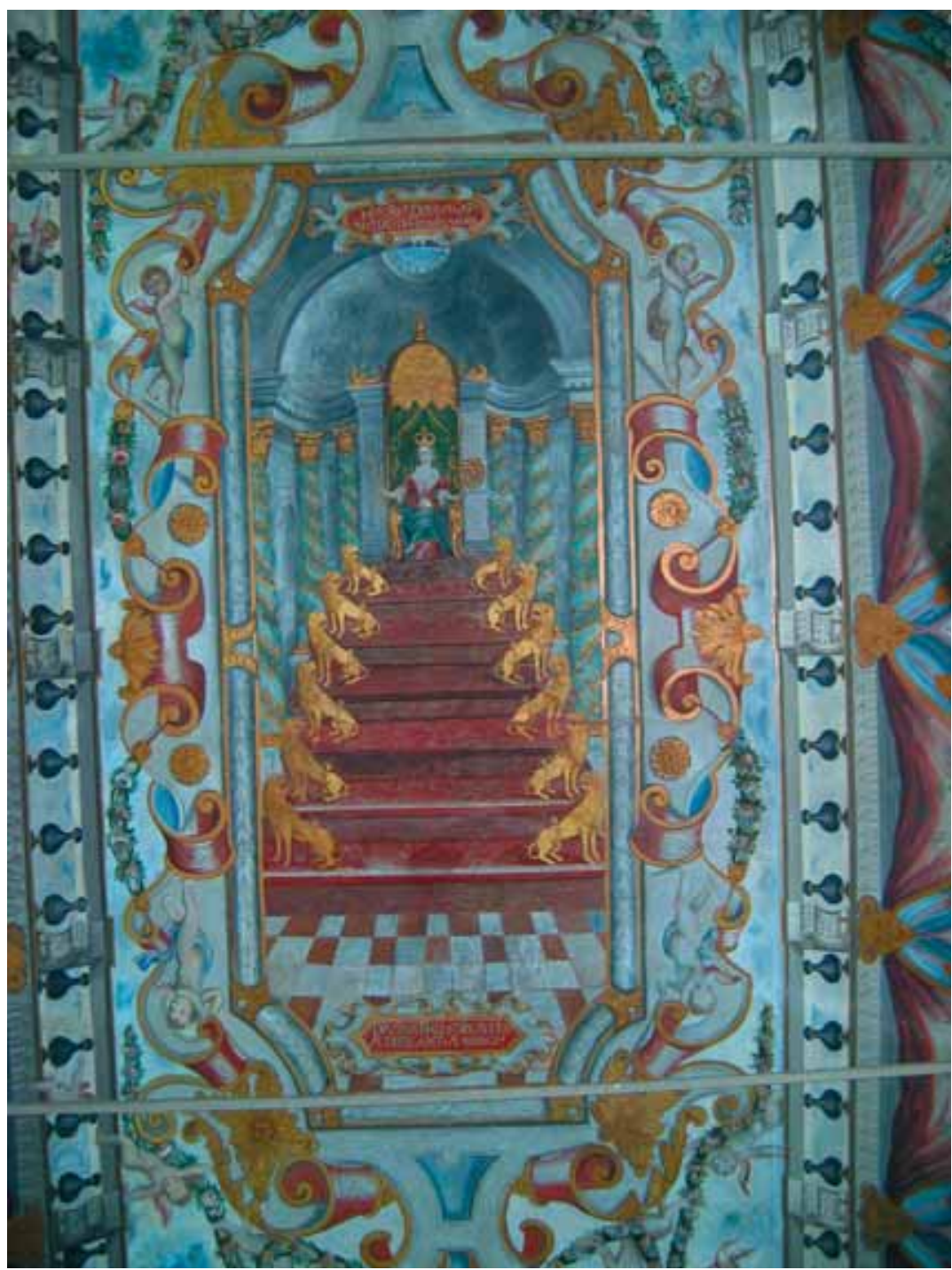

Figura 6: A Virgem Maria, Sedes Sapientiae, 1708, Biblioteca da Universidade, Évora, Portugal (foto do autor). 